\title{
La doble cara de la reforma del sector salud en Costa Rica en la década del noventa
}

Ana Rodríguez Allen

Directora de la Maestría Interuniversitaria en Bioética

Universidad Nacional y Universidad de Costa Rica

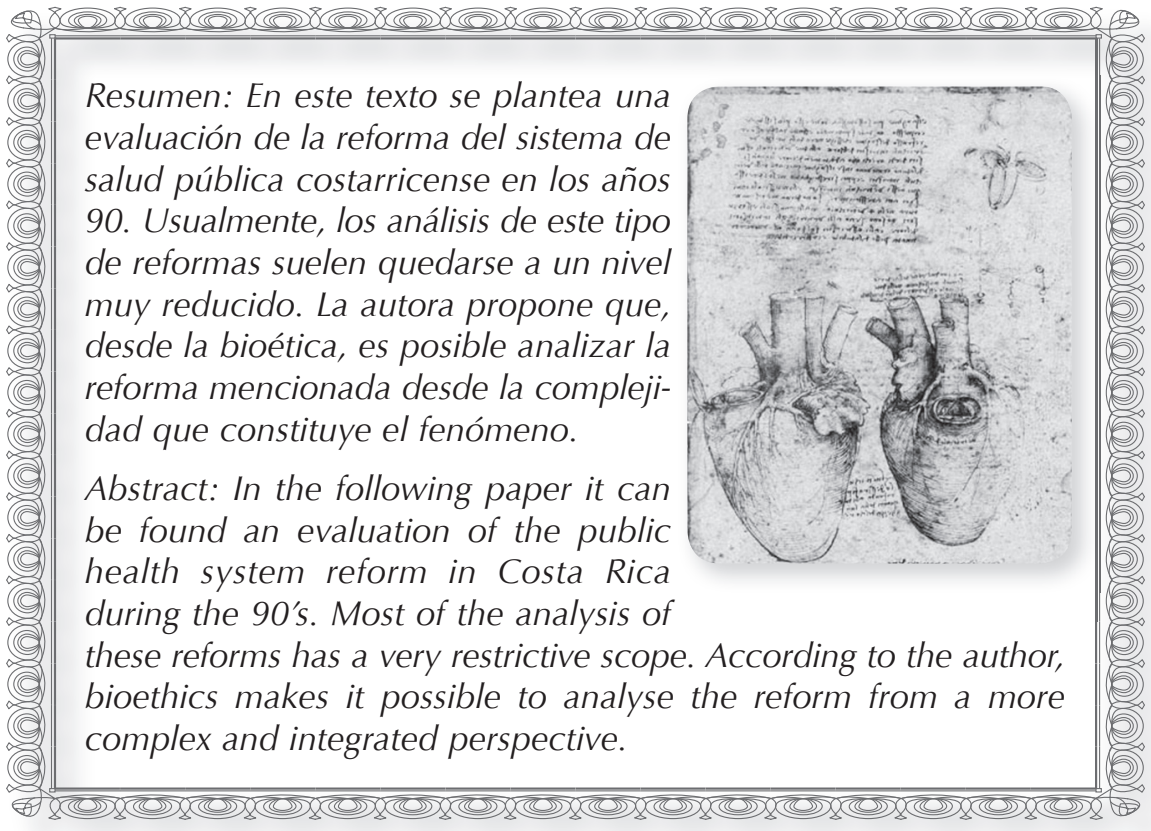


- ste artículo se ocupa de exa- minar la articulación de conocimientos que llevaron a la puesta en práctica del modelo de reforma del sector salud costarricense durante la década de los noventa, para comprender y develar la ética que subyace en la propuesta, lo cual es necesario también para mostrar que la distribución y asignación de recursos no es una cuestión lineal ni su comprensión, simple.

Por las razones anteriores, la reforma no puede ser estudiada desde una perspectiva de análisis unidimensional, lineal, reduccionista, sino desde la bioética y eso significa: multiperspectividad, reconociendo que las instituciones son complejas y están constituidas por elementos heterogéneos que provienen de diversos ámbitos como los sociales, médicos, culturales, políticos, económicos que interactúan y cambian, simultáneamente, a lo largo de su historia. Partimos entonces de la hipótesis de que para comprender la distribución y asignación de recursos del sistema de salud costarricense, en el marco de la reforma del sector salud, era necesario asumir la complejidad institucional. Así como Picasso intentó representar en su obra pictórica un rostro humano simultáneamente de frente y de perfil, rompiendo con la norma de la unilateralidad de una sola perspectiva para que la mente captase su totalidad, este artículo se caracteriza por la aplicación de una metodología que intenta describir y analizar la situación de la Caja Costarricense del Seguro Social y su reforma, descomponiéndola en distintos planos, mostrando sus diferentes aristas, así como sus interrelaciones para comprender su totalidad.

Estas son las razones por las que este artículo atiende la heterogeneidad y los detalles de la reforma sanitaria, lo cual es necesario para que la ciudadanía decida informada cualquier aspecto de la vida política y social que les afecte, a pesar de que para algunos políticos esto resulte tedioso e inconveniente al ir en contra de sus intereses.

\section{El sistema de salud costarricense entre el Estado y el mercado}

- I debate contemporáneo sobre sanidad incluye el análisis tanto sobre los roles como las fallas de la participación del Estado y el mercado en los programas de seguridad social relativos a la salud pública y sobre los cuales aún hay muchas dudas. Un sitio importante en este debate lo ocupa el dilema de si los programas de atención sanitaria deberían abarcar todos los azares de la vida a las que está expuesta la ciudadanía desde su nacimiento hasta su muerte o dejar esta cuestión en manos del mercado.

La polémica se ha enfilado, básicamente, en dos concepciones enfrentadas: la de la filosofía igualitaria de John Rawls y la libertaria de Robert Nozick. El desacuerdo 
entre ambas teorías se encuentra en la disyuntiva de compensar o no a los sujetos que han sido afectados por los arbitrios de la lotería natural y social de la cual ellos no son responsables. John Rawls afirma que el Estado debería intervenir para contrarrestar a los no beneficiados de estos azares con políticas universales y focales. Sin embargo, para Robert Nozick, es inconcebible que los ricos y sanos estén obligados a transferir recursos a los pobres y enfermos por algo que en principio no es responsabilidad de ellos. Lo máximo que puede esperar una persona pobre y enferma es la caridad de los demás, sin que medie ninguna obligación moral. Cada individuo, continúa Nozick, es soberano de su propio cuerpo, y, por consiguiente, decide cómo lo trata y qué parte de sus ingresos destinará a su cuidado sin necesidad de ninguna intervención estatal, ya que se trata del resultado de decisiones privadas y voluntarias.

La mayoría de los países siguen políticas sanitarias que se inscriben dentro de la concepción rawlsiana de la igualdad de oportunidades y Costa Rica no es la excepción. Su Constitución política reconoce la obligación por parte del Estado de "procurar el mayor bienestar a todos los habitantes" (Artículo 50). El país ha ratificado declaraciones y pactos internacionales sobre el derecho a la salud y los programas de políticas sanitarias contemplan como objetivo primordial el fortalecimiento de los sectores más vulnerables de la

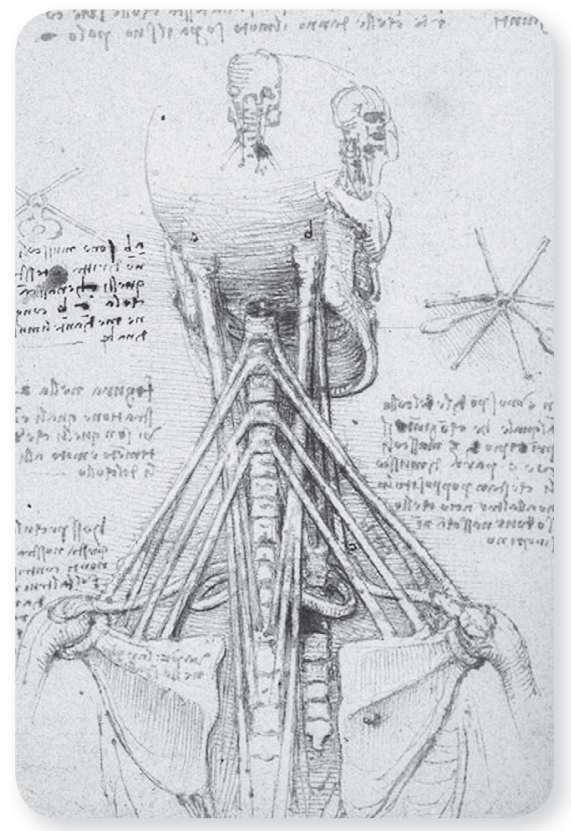

población. Sin embargo, a pesar de que la Constitución es clara en la obligación del Estado frente a las necesidades de la población, se ha empezado a notar un persistente reproche, de diversos sectores sociales, sobre la ineficiencia del Estado y sus instituciones públicas de salud. Este tipo de cuestionamientos lleva implícita para la sociedad civil algo más que la libertad individual planteada por neoconservadores como Robert Nozick. Por su parte, el Estado filántropo se debate en una misión bipolar que le obliga a aceptar alguna responsabilidad para influir en la distribución y asignación de bienes y servicios sanitarios; también a proporcionar un nivel de vida aceptable por debajo del cual no se debe dejar hundir a ninguna persona, a la vez que a suministrar 
a la ciudadanía las posibilidades de una buena educación para que eleve su posición socioeconómica por encima del mínimo, mediante sus propias capacidades. Es decir: el Estado atiende su responsabilidad histórica como estabilizador interno de tipo económico y político, e intenta asegurar el vínculo entre las fuerzas heterogéneas que lo inauguraron. Esa misión bipolar también lo obliga a atender las demandas de grupos económica y políticamente poderosos de neo-laissez faire, que algunas veces interpretan las intervenciones del Estado como un desincentivo para la inversión y la rentabilidad, que perturban las prerrogativas del mercado y la propiedad privada y otras, requieren del Estado para mantenerlas, con sus intervenciones ex post facto.

Consecuentemente, los principales desafíos que enfrenta el sistema de salud costarricense son ampliar su cobertura y resolver su sostenibilidad financiera. Para ello es importante que el Estado, como patrono, cumpla sus obligaciones con las instituciones de salud, y la Caja Costarricense del Seguro Social mejore la recaudación, reduzca la evasión e incluya a otros contribuyentes. Otros desafíos están relacionados con la falta de articulación al interior del entramado de las instituciones de salud, lo cual produce descoordinación, ineficiencia e inequidad. No existe un sistema de datos unificados y por eso se produce duplicidad de funciones. Además, las investigaciones de los funcionarios acerca de este tópico se convierten en esfuerzos abortados que llevan a la frustración y a la desazón moral.

Por último, es necesario referirse al papel de los indicadores macroeconómicos que se aplican en la toma de decisiones en salud, y determinan, en concreto, los acuerdos que se llevan a la práctica sin grandes costes políticos, porque la naturaleza de dichos indicadores facilita la manipulación de la información mediante explicaciones generales, sin desagregar los datos, en los que pueden ocultarse posiciones e intenciones políticas. En este contexto, son los indicadores macroeconómicos los que han hecho poner en duda el papel del Estado de bienestar en el manejo de la salud pública, y ha perdido credibilidad moral entre la ciudadanía la idea de que la cobertura sanitaria universal deba basarse en la solidaridad, cuando, además, ninguna de las reformas estatales, y en especial la sanitaria, ha sido capaz de poner en práctica programas preventivos eficaces, y, al mismo tiempo, controlar la explosión de los costes en salud. Así, se ha ido desmoronando la proporción de ingresos que se deduce por seguro obligatorio sustentada en la solidaridad, porque este principio ya no es compartido por los sectores sociales medios que durante muchos años se beneficiaron de él para resolver sus propias necesidades en salud, pero que hoy prefieren desatender para acudir a los servicios sanitarios 
privados, con lo cual se desprotege un volumen de población importante, especialmente de los sectores más vulnerables: los pobres. Ya no siempre se garantiza que aún el mínimo digno de protección a la salud sea independiente de los ingresos personales. Ha ocurrido un cambio en la cultura costarricense y en la mentalidad de la ciudadanía, especialmente en los sectores medios, que en general han sustituido el principio de solidaridad social que les benefició en el pasado y en el que sustentaron la mayoría de sus logros personales y profesionales, y han adoptado la idea de que un bienestar como el suyo debe ser alcanzado ahora sólo mediante el esfuerzo y las condiciones individuales, sin el concurso social. Así tenemos un grupo grande de sectores medios que destinan sus fondos a los servicios privados de salud.

\section{La eficiencia y la equidad en la práctica}

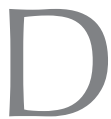
e los documentos oficiales del Proyecto de Reforma del Sector Salud Costarricense, puede inferirse que tanto sus diseñadores como sus ejecutores se proponían conciliar la eficiencia (maximización de los recursos a partir los logros obtenidos) y la equidad (maximización del nivel más bajo de la renta), mediante mecanismos de cooperación mutua (solidaridad, reciprocidad del beneficio) para alcanzar la universalidad en la cobertura. No obstante, en dichos documentos también se constata la preeminencia de un enfoque fragmentario, que obvia la complejidad inherente al caso de la salud, porque hay ausencia de análisis de las interrelaciones entre, al menos, las dimensiones económica, médica, jurídica y ética de la institución. Aunque, según lo han indicado varios autores como Mary Clark, Juliana Martínez, Ana Sojo, Leonardo Garnier y Oscar Arias Valverde, a pesar de que exista dicha fragmentación, no se puede desconocer que una preocupación constante de los ejecutores de la Reforma, era impedir la quiebra del sistema de seguridad social costarricense. La primera fase de la Reforma de la década los ochenta intentaba evitar el descalabro financiero de las instituciones sanitarias. Para ello se modificaron algunas normas que permitieron la compra de servicios a terceros; luego, durante la segunda fase, en la década del noventa, dicen ellos, la Reforma toma otro cariz y se adhiere más a una concepción focalizada e integral de la salud, sin perder su carácter universal. Se empezó a divulgar la idea de que había indagar cuáles eran los sectores más vulnerables de la sociedad, el slogan de gobierno de José Figueres Olsen (1994-1998) era "El combate a la pobreza".

En la primera fase puede afirmarse que la disponibilidad de recursos era insuficiente, y en la segunda, a pesar de la disponibilidad de medios económicos, en la Caja seguían reinando los viejos pro- 
blemas como la falta de controles fiscales, a lo que se sumaba que los mecanismos de la propia Reforma permitieron la introducción del mercado sanitario privado, cuyos propósitos, en algunos casos, según Leonardo Garnier, fueron obviamente corruptos.

En la fundamentación que sostiene la construcción del Proyecto de Reforma del Sector Salud subyace una contradicción que la falsea, porque se establecen con el mismo rango de importancia principios que corresponden a doctrinas éticas opuestas, como son los de solidaridad y universalidad, base de la seguridad social y el de la eficiencia y el lucro, más ligados a la ética del mercado. Aunque se reconoce la importancia de la eficiencia para la sostenibilidad del Proyecto, el problema se plantea cuando en la práctica se subordinan la solidaridad y la universalidad a la eficiencia y al lucro. Así, por ejemplo, en el modelo de atención primaria en salud, diseñado para resolver el problema de inequidad e ineficiencia del sistema de salud costarricense, se invocan los Compromisos de gestión para justificar decisiones políticas, como la de aumentar o reducir el presupuesto para las enfermedades infecciosas o la compra de medicamentos genéricos, como también aquellas de carácter individual, relativas a la asignación de una intervención quirúrgica a un paciente que se encuentra en la lista de espera.
Entonces, a la pregunta ies posible aplicar el modelo de atención primaria conjugando calidad y equidad a bajo coste? la respuesta es negativa. En primer lugar, porque la calidad y la equidad quedan supeditadas al coste; en segundo lugar, porque es difícil, en el corto plazo, cambiar la praxis del recurso humano, así como la mentalidad de los usuarios por un "nuevo modelo sanitario"; y en tercer lugar, porque las autoridades presupuestarias constriñen los recursos pactados y los órganos contralores no ejercen las regulaciones pertinentes, instaurándose, continuamente, la impunidad.

Un buen ejemplo de lo anterior lo corroboran las informaciones aportadas por diversos pensadores y actores políticos del país, entre ellos, Juan Jaramillo Antillón, Leonardo Garnier y Guido Miranda. Este último indicaba que el punto medular de la Reforma del sector salud era el programa de atención primaria fundamentado en la estrategia de los equipos básicos de atención integral en salud, que, desde una concepción, básicamente técnica, pretendían reducir las desigualdades en salud, partiendo de la idea de que una gestión apropiada era la solución óptima para realizar intervenciones comunitarias efectivas, pero "ignorando" que la reducción de la pobreza o la accesibilidad a los servicios de salud no son solo problemas técnicos o financieros, sino cuestiones políticas, porque la disponibilidad de recursos 
se decide en el proceso político. Las soluciones técnicas necesitan de la viabilidad y la acción política para llevarse a cabo. Por eso en la práctica el objetivo de la Reforma del Modelo de Readecuación era de difícil consecución, dadas las actuales relaciones de poder al interior de las instituciones de salud, más autoritarias y corruptas que democráticas y transparentes. Así, para el año 2002, dice Miranda, se anunciaba que la Caja había puesto en funcionamiento 710 EBAIS, y que cada equipo atendía 4 mil habitantes por área, pero la realidad era que el número alcanzaba los $5 \mathrm{mil}$ y más, y que en stricto sensu sólo 408 EBAIS se consideraban consolidados, de los cuales 332 no poseían infraestructura apropiada, así como
54 carecían del equipo humano para la atención en salud. Se sumaban a estos problemas los derivados de la afiliación de la población, de evasión en la cotización, de la subdeclaración salarial en la planilla, de la introducción incontrolada de estudiantes de instituciones privadas de salud (algunas muy débiles en la formación del profesional de la salud), de la administración de los recursos sanitarios, de los protocolos de investigación sin una adecuada regulación, y además del incumplimiento de horarios y cuidado del patrimonio institucional por parte de profesionales de la salud, que, como señala Guido Miranda, los Compromisos de gestión ni siquiera consideraron en su concepción ${ }^{1}$.

\section{La universalidad versus la medicalización de la sociedad}

L

os diseños de seguros sociales elaborados después de las dos Guerras Mundiales tuvieron como fuente jurídica la Carta del Atlántico, la Declaración de Filadelfia y la Conferencia de Santiago de Chile. Las recomendaciones y resoluciones de esas convenciones fueron piezas relevantes para la construcción del modelo sanitario costarricense en la década del cuarenta, que se plasmaría en la Constitución de la República, en el capítulo de las Garantías Sociales. Los Seguros Sociales partían de dos principios básicos: universalidad y solidaridad.

El principio de provisión universal de servicios sanitarios enuncia, idealmente, la orientación moral que se supone deberían haber seguido las políticas sanitarias del país. Dice la Constitución en el artículo 177 que "para lograr la universalización de los seguros sociales y garantizar cumplidamente el pago de la contribución del Estado como tal y como patrono, se crearán a favor de la Caja Costarricense del Seguro Social rentas suficientes y calculadas en tal forma que cubran las necesidades actuales y futuras de la Institución". Una de las políticas sanitarias a las que se alude era cubrir el mayor número de personas que se encontraran en situación de riesgo, y, por lo tanto, otorgar pres- 
taciones sin examinar los recursos económicos del beneficiario u otro tipo de condición. Para llevarla a cabo era necesario financiar el sistema mediante fondos públicos. Estas medidas contrarrestarían factores tales como la lotería natural y social o la capacidad de pago, aumentando las posibilidades de que los trabajadores de ambos sexos no enfermaran, siendo esto último condición sine qua non para que una economía capitalista funcionara. Sin embargo, el principio de universalidad tenía una regla adicional: su carácter obligatorio. Así, el artículo 73 de la Constitución afirma que los seguros sociales se regularían "por el sistema de contribución forzosa del Estado, patronos y trabajadores..." Sin este elemento de coerción no hubiera funcionado el sistema de salud costarricense, lo que nos muestra que las solidaridades vividas espontáneamente son una "ilusión" y que en sociedades de corte capitalista es necesario imponerlas por la ley.

El principio de universalidad resultó tan ambicioso como utópico, sobre todo en manos de economistas convencionales que no consideran, a la hora de analizar los presupuestos de salud, que el alza progresiva de los costes muchas veces depende del enfoque con que se trate la salud y la enfermedad. En Costa Rica, contrariamente al propósito de la Reforma del sector salud que era mitigar el aumento de los costes y fortalecer la atención primaria, el gasto ha seguido cre- ciendo. El problema se mantiene inalterable porque se persiste en tratar la mayoría de los riesgos sanitarios dentro del modelo curativo.

El principio de universalidad está estrechamente relacionado con el derecho inalienable a la salud, pero juntarlos plantea un contrasentido cuando existen limitaciones debido a la escasez de recursos sanitarios. No parece posible en un Estado caracterizado por su ambigüedad, conciliar la demanda sin límites y el derecho a la salud, como tampoco la economía liberal y los derechos sociales. Además, desde el momento en que se descubre que la enfermedad es rentable, la lógica que prevalece es la derivada de un contexto económico de producción y consumo y no de los derechos inalienables. Por eso dudamos de que el aumento de los costes en salud se deba, exclusivamente, a cambios en el perfil epidemiológico o al envejecimiento de la población. Debió haberse incluido en el programa de Reforma un diagnóstico profundo acerca de la dinámica del consumo y el papel del recurso humano.

La continuada presión ejercida por la publicidad comercial de oferta de bienes y servicios en salud y enfermedad ha traído la medicalización de la sociedad y con ello una múltiple oferta de productos farmacéuticos, tecnologías médicas, hospitales, clínicas estéticas para no envejecer, para adelgazar o para prolongar la vida, etc., de tal forma que la población asustada, con tal de llenar las exigencias de las 
sociedades actuales, consume todo lo que se le ofrece como si consumiera hamburguesas, o Coca Cola. Asimismo, este estallido de publicidad conduce a una educación sanitaria narcisista que va dirigida al individuo y no a la salud colectiva. Si se pudiera determinar la cantidad precisa de atenciones sanitarias que necesita realmente la población, con certeza la cantidad disminuiría el consumo actual. Desde 1970 se sabía, mediante las encuestas elaboradas por la firma francesa CREDOC (Centre de Recherches et de Documentations sur la Consommation) ${ }^{2}$, que los responsables de la subida de los costos en salud eran los médicos, los hospitales y las farmacias. CREDOC afirmaba que las prácticas médicas que demandan alta tecnología e instrumentos sofisticados, la inadecuada administración de los hospitales y los salarios del personal sanitario generaban un ritmo acelerado de gastos. Pero son muy pocos los estudios en el país que incluyen estas causas.

Hace más de cincuenta años, los costarricenses se organizaban por cuestiones como la democratización del voto, la extensión de la ciudadanía o las garantías sociales que se consideraban, hasta hace poco, hechos consumados. Pero los costarricenses de hoy, que no se conmueven fácilmente con las decisiones de sus representantes políticos, se sublevaron como nunca, cuando el gobierno de Miguel Ángel Rodríguez pretendió, en el años 2000, privatizar, por reco- mendación del FMI, el Instituto Costarricense de Electricidad (ICE). La gente empezó a darse cuenta de que su futuro no se decide tanto en su país como en las negociaciones con los organismos financieros internacionales. En cambio, si bien es cierto que con la reforma el sector sanitario no entró en un proceso abierto de privatización, sí empezó a conceder al sector privado algunos servicios importantes mediante la politización explícita del sistema legal. Encontramos los resultados prácticos de la reforma en procedimientos jurídicos oscuros de los que son conscientes los políticos y los expertos encargados del funcionamiento del sistema, de los cuales no se percata la población, porque las personas están más preocupadas por lo que les afecta de manera inmediata que por lo que las políticas sanitarias les traen, en el mediano y largo plazo, en sus vidas cotidianas. Empezaron a surgir discrepancias entre la doctrina vitoreada en los principios de la seguridad social y su dimensión operativa. Se ofreció la idea de un mercado interno controlado como alternativa al dominio burocrático por parte del Estado, a pesar de que las experiencias de otros países habían demostrado que el modelo del Banco Mundial había fracasado.

Víctima de nuestros propios éxitos en salud, esperanza de vida alta y baja mortalidad infantil, el nuevo modelo sanitario se fue introduciendo, paulatinamente, y calando casi imperceptiblemente en 
la población sin ninguna resistencia. Mientras, los ejecutores realizaban ajustes con rapidez y con un sentimiento de apremio, apoyados en una mal disimulada campaña publicitaria que anunciaba la inminente insostenibilidad financiera de la institución, esquivando posibles obstrucciones al "nuevo" modelo por parte de los funcionarios y de la ciudadanía, creyendo que la velocidad era una condición para el éxito del programa de Reforma. La excesiva velocidad con que se introdujo e impuso el modelo ha resultado intolerable y ha condu- cido a la institución a tal punto de fisura de su tejido social que, de seguir como vamos, se podría regresar a una situación sanitaria tan precaria como la que sufrió el país antes de la Reforma Social de 1943. Los índices en salud empiezan a caer y la mayoría de los funcionarios de este sector están conscientes de que el modelo ha fracasado y de que las modificaciones al orden institucional no fueron superficiales, puesto que se han sacudido los principios de la seguridad social: universalidad y solidaridad.

\section{Modelos económicos abstractos para situaciones sanitarias concretas}

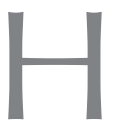

oy en día los grandes mercados financieros globales hacen proyecciones al futuro, pero el futuro es incierto con respecto a cómo los mercados financieros valoran el presente. Esta idea es harto conocida por los críticos de la economía convencional como Joseph Stiglitz, Amartya Sen o el magnate George Soros. De la misma manera encontramos en el pensamiento neoliberal la idea de que el mercado es el atributo necesario de la libertad, por el cual el hombre libre puede ejercer su iniciativa individual y ser dueño de su destino, al estilo de prototipos de personajes como serían, por ejemplo, Will Chamberlain -o John Wayne- de la obra de Robert Nozick. El escritor y periodista inglés Daniel Defoe (1631-1660) muestra este patrón en su novela Robinson Crusoe, al narrar las contingencias del personaje y describir la existencia de un hombre aislado que ha sido el tópico persistente de algunos filósofos y economistas teóricos. El personaje ha servido de modelo para teorizar sobre el individualismo y sobre alguien que es capaz de distribuir sus escasos recursos entre necesidades que compiten. La referencia a Crusoe constituye un clásico en los libros de economía y es un buen ejemplo de la forma en que algunas corrientes de esta disciplina tratan problemas concretos, en abstracto. Pero como han señalado Giovanni Berlinguer, Carol Buck y Amartya Sen, es difícil apelar al modelo de la iniciativa individual cuando existen sujetos para quienes su más apremiante necesidad es defenderse del hambre y no están capacitados para conocer, por ejemplo, el máximo rendimiento de una nutrición barata. 
La matematización de la economía facilitó la construcción de técnicas y modelos para fundamentar y validar explicaciones, las cuales, a su vez, se utilizaron en la argumentación y definición de criterios de calidad para las instituciones públicas y privadas. Aún y cuando los conceptos económicos y matemáticos han sido útiles en tales argumentaciones, no son suficientes para contener la complejidad de los procesos institucionales y el exceso de abstracción que provocan en el tratamiento de los problemas ha hecho que se acabe por perder el contacto con la realidad concreta que pretenden solucionar. Estos son los presupuestos erróneos que adoptan quienes tratan las controversias y la complejidad sobre la distribución de recursos, intentado hacerlos corresponder con una concepción formal de la racionalidad práctica económica, lo cual lleva a trazar distinciones rígidas que, en consecuencia, no ayudan a tomar decisiones concretas e ignoran que el análisis de los problemas éticos debe resolverse integrando el contexto cultural e histórico desde donde nacen los problemas. La reforma del sector salud lleva, en sí misma, las posibilidades para que la actividad sanitaria se transforme en un negocio, y los negocios, por supuesto, están motivados por el lucro y algo se quebranta cuando a la ciencia médica le invade la motivación de las ganancias.

Por otra parte, las escuelas clásica y neoclásica de economía y la ética utilitarista clásica han influido en las políticas de salud. Estas escuelas sostienen que, al poder calcularse numéricamente cualquier actividad económica, se puede obtener una maximización de los beneficio ${ }^{3}$ cuantificables. Otros autores $^{4}$ matizan esas afirmaciones al señalar que la lógica cuantitativa puede implicar consecuencias desfavorables en lo cualitativo, como el deterioro de la comunidad institucional, resultando el modelo mercantil demasiado frágil como para impulsar conductas cooperativas al primar la competencia. La maximización de los beneficios no siempre se encuentra aparejada con el principio ético de la solidaridad, base fundacional del sistema del seguro social costarricense.

La economía neoclásica parte de los supuestos irrealistas de que la información en el mercado es transparente - es perfecta- y de que la oferta igualará a la demanda ${ }^{5}$. Sin embargo, una economía moderna justa $^{6}$ y progresista tiene que compatibilizar el crecimiento con la solidaridad, la responsabilidad y la equidad, con el mantenimiento del ogro filantrópico del Estado de bienestar, a pesar de que en estos momentos este modelo atraviese una crisis de confianza. A pesar de lo anterior, la Organización Mundial de la Salud $-y$ sus oficinas regionales- enfilaron la política sanitaria para la región en la macroasignación y microasignación de los recursos sanitarios desde una visión mercantil, producto, como hemos 
explicado, del creciente poder del comercio internacional. Por esta razón ningún otro tema por sí solo ha atraído más la atención y preocupación de los planificadores que el presupuesto en sanidad, temores que han sido tratados solo desde una óptica muy administrativista y superficial, que ha dejado de lado, por ejemplo, el rol del recurso humano en la aplicación de las nuevas técnicas de gestión.

\section{La Caja "chica" del Estado}

debilitamiento financiero de la Caja, con todas las repercusiones que esto ha traído a la salud de los costarricenses, ha sido un proceso de larga data en el que han intervenido situaciones de distinta índole. No sólo han menguado sus recursos las diferentes condiciones epidemiológicas que ha vivido el país o las nuevas demandas que se avizoran por el envejecimiento de una gran proporción de la población costarricense en un futuro inmediato, sino que, muy especialmente, la insostenibilidad financiera de la Caja se debe al mal uso que han hecho de sus recursos las juntas directivas de esta institución, confabuladas con los grupos políticos en el poder.

Las decisiones que se toman en relación con los fondos públicos en el ámbito sanitario no están vinculadas a una reflexión y menos a una discusión de principios que pudieran orientarlas y situarlas en el plano moral. Por ejemplo, la Caja ha sido para el Estado un sitio de donde ha obtenido recursos para utilizarlos en objetivos diferentes a aquellos por los que se han recaudado. Para ello, se han modificado reglamentos y decretos internos con lo que se han favorecido prácticas institucionales de transferencia de recursos, en desmedro de programas sociales y a favor del cumplimiento de promesas de campañas políticas de los grupos que están en el poder en ese momento. Esto debe destacarse porque inicia una práctica dañina mediante la cual el Estado exige a las instituciones públicas generar cada año un superávit, que debe ser invertido en la compra de bonos o certificados del gobierno a bajo interés y largo plazo. En ese contexto, según explica el médico Juan Jaramillo Antillón, la Caja, en el período comprendido entre 1986 y 1990, modificó sus reglamentos y realizó la compra de dichos bonos con los fondos de reserva del Régimen de Invalidez, Vejez y Muerte que se utilizaban para construir viviendas de bien social u otorgar préstamos de vivienda para sus trabajadores, así como para las construcciones del Régimen de Enfermedad. En el año 1997 y en el de 1999, los superávits de la Caja, destinados a la compra de bonos del Estado, fueron de 30 y 64 millones de dólares, respectivamente. 
Cuando estos bonos vencieron, el Estado los pagó con nuevos bonos y si a esto se suma el hecho de que los gobiernos de turno no cancelan a la institución sus cuotas ni como Estado ni como patrono, y estas representan, aproximadamente, el $20 \%$ de su presupuesto anual; puede comprenderse que la institución enfrente, cada año, un déficit que se va acumulando ${ }^{7}$. Luego, los mismos que originan este problema acusan a la Caja de ser una institución ineficiente, con esquemas de organización agotados, por lo que proponen la creación de instancias alternas para la gestión de servicios públicos en salud, buscando e interpretando las normas que posibilitarán la viabilidad jurídica para realizar compras a terceros porque desde sus orígenes — 1943-, la Ley Constitutiva de la Caja deja abiertas las vías a esa posibilidad ${ }^{8}$.

\section{Poder y salud}

\section{L} os nuevos escenarios económicos de la globalización han facilitado y fortalecido el resurgimiento de los valores y prácticas de la medicina liberal, que permanecían latentes desde la fundación misma de la Caja. Con el ingreso de las técnicas del mercado en el ámbito sanitario y el desarrollo del proceso de medicalización de la sociedad, los profesionales sanitarios se identifican, a sí mismos, como vendedores del bien-salud y a los pacientes como clientes compradores de un servicio. Esto coincide con los requerimientos de los compromisos de gestión del Proyecto de Reforma, que necesitan, para su puesta en práctica, de profesionales formados para desempeñarse en el ámbito de la Ilamada "medicina gestionada" o managed care, que alude a las distintas maneras de introducir el mercado y la empresa en la sanidad, por lo que dichos profesionales también deben conocer acerca de las técnicas de gestión administrativa. No obstante, los ejecutores de la Reforma no tomaron en cuenta los riesgos de tal introducción, con lo que han puesto en peligro las metas que dan sentido a los servicios de salud pública costarricense

¿Cuál es la razón de que en los documentos de la Reforma de salud no se discuta a fondo acerca del papel que debía jugar el recurso humano en la puesta en práctica de las políticas? Hay varias posibles respuestas a esta pregunta. Por ejemplo, la ausencia de una coordinación intersectorial, con un enfoque común entre el sector salud y el educativo, representado en este caso por las universidades públicas y privadas. Además, el propio gremio médico estaba dividido entre quienes apoyaban la Reforma y quienes no, de manera que dichos profesionales evitaban asumir posiciones que profundi- 
zaran ese conflicto. No se discute, precisamente, porque como hemos explicado, son los médicos liberales quienes más resistencia opusieron al fortalecimiento de la atención primaria en el diseño de la Reforma, porque ese tipo de concepción sanitaria no coincidía ni con su formación ni con sus intereses. Para los ejecutores esto pertenecía a otro ámbito, al de la bioética o de las oficinas de recursos humanos, por ejemplo. Se partió de la creencia de que al resolverse en un nivel superior de abstracción —como en economía formal- la distribución sanitaria, su aplicación concreta, no enfrentaría ningún obstáculo como han sido la resistencia de los funcionarios de salud, y ahora de la ciudadanía. Para unos significó mayores ganancias porque se podían comprar servicios de salud privados con fondos públicos; para otros, el nuevo modelo implicó un profundo cambio en las relaciones humanas. Los biombos ${ }^{9}$ no desaparecieron, sino que se generalizaron: las listas de espera aumentaron, el paciente no asegurado era rechazado y los indigentes empezaron otra vez a ser víctimas de los vaivenes de los presupuestos sanitarios y resultan entre los más vulnerables al resurgimiento de enfermedades que habían sido controladas.

Si los hospitales se encuentran abarrotados es porque la atención primaria ha sido deficiente, ya que, como señala Carlos Samayoa de la Organización Panamericana de la Salud, el 85 \% del gasto en Costa
Rica es hospitalario, frente a un $22 \%$ que se destina a la atención primaria $^{10}$. Esta proporción podría ser invertida, lo cual, aunado a una política intersectorial que integrara los diversos proyectos encaminados a la promoción y prevención de la salud con la participación comunal, reduciría el problema del colapso hospitalario y mejoraría tanto la salud institucional como la de los costarricenses. Pero obviamente las motivaciones son otras. El objetivo real, para citar un ejemplo, es un modelo médico acorde con el mercado de medicamentos y enfermedades, por eso en las grandes empresas bio-tecno-químicofarmacéuticas lo que interesa es la venta de productos que generen ganancias. De ahí que se investiga y se pone en el mercado lo que es rentable, y en este juego entra la medicina cosmética. Así, en el Foro global sobre investigaciones en salud del año 2000, se calculaba que más del 90\% de la inversión en investigación se dedica a enfermedades del $10 \%$ de la población mundial que goza del más elevado nivel socio-económico, sin importar a los productores de medicamentos, enfermedades como el paludismo, la malaria o el SIDA que afectan a una gran proporción de la población mundial ${ }^{11}$. Finalmente, queda una cuestión cuya presencia constante es necesario develar: la del poder.

El poder está inmerso en la definición de salud y enfermedad, en la construcción de la política sani- 
taria, en la práctica de la medicina, y en la consecución del proceso de salud. La reforma aparece, como afirmaban Rudolf Virchow, Max Weber o Michel Foucault, como instrumento de poder que tiene como objetivo el mantenimiento del status quo y la estabilidad de las actuales relaciones de dominación. Los documentos sucesivos en línea con el texto madre de la reforma (Modelo de readecuación de atención integral en salud de 1993) elaborados hasta ahora han ignorado la dimensión del poder en la problemática de la salud, encubriendo con ello su distribución en la institución. La situación de salud del país es producto de la lucha de poder entre los diferentes grupos de interés, cuyos discursos, plagados de eslóganes como igualdad de oportunidades, equidad de género, cobertura universal, ética solidaria...etc. son mutilados en la práctica por los intereses nacionales e internacionales de aquellos que desean mantener en las corporaciones médica o farmacéutica las relaciones de poder sin demasiados cambios.

En este contexto, el proyecto que apuntaba a la disminución de las desigualdades sanitarias queda también mutilado y relegado y se acude a la fórmula del victim blaming, responsabilizando a la ciudadanía de su salud y de los problemas institucionales. Se impone una definición de vida saludable, se acusa al ser humano de su mala salud y de esta forma la vida saludable adquiere categoría moral definida por unos expertos que utilizan criterios científicos no inmunes al poder.

\section{Los problemas de gobernabilidad de una institución compleja}

a escasa participación ciudadana, la falta de conexión entre los diversos subsistemas de salud, por ejemplo entre la Caja y el Ministerio de Salud -base inherente de la prevención sanitaria que se impulsaba en el modelohan traído una procesión de consecuencias que repercuten directamente en la calidad de la salud de la población, promoviendo su deterioro e incluso facilitando el retorno de enfermedades que estuvieron controladas durante muchos años, como la malaria, el dengue, el sarampión y hasta la tosferina, etc.
Lo anterior se agrava con la escasez de medicamentos y nos podría hacer regresar a escenarios sanitarios similares a aquellos que vivieron los costarricenses del primer tercio del siglo XX y que creíamos largamente superados. Esta situación nos instruye sobre la imposibilidad de estudiar separadamente las dimensiones de la economía, el derecho, la medicina y la ética porque no se puede instaurar un modelo si cada saber ha tomado su propio camino, pero, además, nos informa de lo erróneo que supone establecer las características y posibilidades de los 
servicios de salud divorciadas del contexto sociocultural y del modelo económico vigente. Resulta contradictorio hacer compatible un sistema de salud público con una política macroeconómica que se plantea como un deber la superación de la inflación, obligando a recortar los recursos en salud en línea con la "nueva" política de desarrollo del país. El modelo de Reforma no ha sido el ideal de justicia distributiva que pregonaba porque no ha superado las desigualdades sociales en salud. Los documentos justifican el recorte en política social, basados en la crisis del Estado de bienestar y amparados en los consabidos argumentos de racionalidad y eficiencia. La situación actual muestra, claramente, una institución en decadencia.

\section{La asimetría de la información como parte del juego del mercado}

L

a asimetría de la información se da en las relaciones entre los profesionales de la salud y los pacientes, en el mercado sanitario, entre las instituciones involucradas en la salud, en la formación de los profesionales, entre las comunidades y la ciudadanía. Esta situación está emparentada con el paternalismo médico que, como señala María Bettetini, parte del principio de que se miente "para bien", y por ello se engaña y encubre la verdad.

En el nuevo modelo de gestión, cuando un paciente paga - directa o indirectamente- por un servicio médico está comprando salud y se supone que va a recibir una contraprestación definida. Pero en la práctica médica, en primer lugar, no se fiscaliza ni regula adecuadamente los servicios -los precios en el caso de las cooperativasdel producto salud, y en segundo lugar, la contraprestación resulta indefinida, pues en innumerables ocasiones el paciente tiene escaso conocimiento sobre lo que le aqueja, y es por ello que no sabe qué va recibir a cambio. Esta es una falla del denominado cuasi mercado de la salud que requiere del desarrollo de estructuras regulatorias y controles que permitan su funcionamiento en condiciones justas y eficientes.

Es necesario señalar que los profesionales de la salud, en particular el gremio de los médicos, gozan de acceso privilegiado a dos tipos de información que, a resultas de dicho privilegio, pueden emplear en forma apta, inepta o negligente y eventualmente ocultar en beneficio de sus propios intereses: la información sobre el estado de salud del paciente y la información sobre los recursos públicos sanitarios. Utilizar la institución pública como un medio para ofrecer mayor rapidez en el servicio y mejor información sobre el estado de salud de un paciente en un consultorio privado o solicitar un pago para saltarse la lista de 
espera es evidentemente un caso de corrupción y falta de transparencia con la misma institución; aunque de todas formas la lógica del mercado lo permite, porque insistimos, en los mercados reales existen situaciones de información asimétrica que producen excesivas ganancias a los dueños de la información, además, lo mismo ocurre en las empresas de economía privada.

Ahora bien, cabe preguntarse si todo este proceso de mercantilización de la salud ha mantenido y mejorado la de la población costarricense, a pesar de que el ámbito sanitario no es un mercado. Sostenemos que el modelo ha servido de portillo inicial para un paulatino, silencioso y lento proceso de privatización. Téngase en cuenta que hace poco se volvía a discutir en la presidencia ejecutiva de la Caja ${ }^{12}$ - otra vez se encubre una posible transformación de la Caja sin conocimiento de los ciudadanos- la posibilidad de cobrar los servicios de salud ${ }^{13}$, confirmando así el propósito privatizador subyacente a la reforma, acorde con las políticas impulsadas por el Consenso de Washington ${ }^{14}$.

\section{Un futuro posible}

a obtención de recursos ha dejado de ser una cuestión privada $^{15}$, como en otras épocas, para transformarse en un problema de orden público y político. La salud pública se ha convertido en un problema de Estado, atrapada en un enjambre burocrático de políticas y normas sanitarias. Algunos consideran desmesurada la intromisión del Estado - a través Juntas directivas politizadas- ${ }^{16}$; otros, insuficiente; pero cada cual justifica su punto de vista a partir de una concepción de justicia diferente, generando avivados debates en torno a la justicia sanitaria. Pero lo ejecutores del modelo de Reforma nunca se preguntaron cuál debería ser un sistema justo de servicios de salud y cómo se debería proceder para distribuir los "recursos escasos", ni cuál forma estatal era la adecuada para la asignación de dichos recursos. La solución propuesta en el sistema de salud costarricense, como hemos visto, ha sido la aplicación de métodos de mercado libre a un sistema mixto de salud $y$, por otro lado, el fortalecimiento de políticas de prevención sanitaria con campañas educativas para la población.

El médico Rodrigo Gutiérrez Sáenz, en el artículo "Antecedentes de la enseñanza y práctica de la medicina", expresa su preocupación por el rumbo que está tomando el sistema costarricense de salud, y advierte que está sufriendo fuertes tensiones y que es muy probable que su transformación lo haga casi irreconocible en los próximos años, de seguirse las tendencias del mercado. 
Dice Gutiérrez sobre el sistema de salud: "(...) la organización (...) y el tipo de servicios que se entregan (...) la formación del personal para el sector Salud y el financiamiento del coste de la construcción social de la Salud, ya no van a estar en manos de una o dos instituciones como pueden ser la CC.SS. y el Ministerio de Salud sino que en varios ámbitos se discute cómo deslindar lo que "se deja al Estado" y qué asumen los individuos y empresas privadas. La nuevas concepciones teóricas del modelo neoliberal procuran evitar que los Estados se vean comprometidos en situaciones similares al período 1950-1980 y han desarrollado estrategias para trasladárselas a los individuos, mediante una preconizada descentralización y democratización, que a veces en lo que se transforman es en un traslado de obligaciones financieras, para que ahora las asuma la organización de la comunidad. En esa forma se favorecen las libres fuerzas del mercado, en donde ya no cabe el principio de solidaridad, la universalidad de servicios y entran a regir los términos de calidad, gerencia, gestión y la adjudicación de recursos. En esta forma, las deficiencias del sistema dejan de ser obligación y responsabilidad del Estado y le traslada al individuo la obligación de ser eficiente para lograr insertarse en los nuevos niveles de bienestar, que en muchos casos son sinónimos de consumo, de modo que el valor social se transforma en capacidad de compra"17.

Otra idea subyacente en toda esta discusión es la expresada por la filósofa Victoria Camps. En la introducción del libro Los fines de la medicina del Centro Hasting, afirma que: "Los fines de la medicina, a finales del siglo XX, deben ser algo más que la curación de la enfermedad y el alargamiento de la vida. Han de poner un énfasis especial en aspectos como la prevención de las enfermedades, la paliación del dolor y el sufrimiento, han de situar al mismo nivel el curar y el cuidar y advertir contra la tentación de prolongar la vida indebidamente ${ }^{\prime 18}$.

Obviamente, se deduce que no existe una posición ética solidaria explícita, por parte de los diseñadores y ejecutores, que sustente el proyecto de Reforma del sector salud. La puesta en práctica de esta Reforma ha sido automática y ciega, huérfana de un marco ético consistente. En las evidentes contradicciones en la toma de decisiones y en su ejecución automática, están implícitas dos éticas incompatibles: la igualitaria y la libertaria. Esto muestra la falta de un pensamiento político sólido y coherente en el sector salud. La reforma es un intento de juntar el agua con el aceite, o mejor dicho, de quedar bien con Dios y el Diablo, lo que en ética se denomina doble moral. 
a resolución satisfactoria de los actuales problemas en la distribución de recursos empieza por: democratizar las relaciones entre los funcionarios de salud y entre ellos y los usuarios de los servicios, superando las asimetrías que, históricamente, en aquellas ha entronizado el paternalismo duro; sin perder la identidad disciplinaria, sustituir la visión fragmentada del conocimiento por un enfoque más inter y transdisciplinario que muestre la complejidad del sistema de salud y posibilite: a) La comprensión de su Reforma superando el análisis que la reduce sólo a una emergente privatización de los servicios públicos sanitarios; b) la elaboración de epistemologías y éticas adecuadas a la magnitud del problema que enfrenta la práctica de los profesionales de salud y que origina perplejidades, contradicciones e indecisiones, las cuales propician el caos y el desorden institucional que se ve agravado por la ausencia de auditorías, y que son aprovechados por grupos de interés en beneficio propio y en detrimento del bien común; c) los diálogos entre saberes para evitar conflictos entre éstos y delimitar las competencias de los intereses que entran en juego en la distribución de recursos en salud; d) la necesaria integración entre ética y política en el sistema sanitario costarricense, cuya tajante separación ha acom- pañado los juegos de poder en toda la trama institucional durante el proceso de reforma, como expresión de la nefasta ausencia de autocontrol moral de los ejecutores en la administración de los recursos sanitarios, quienes no se preocuparon, ni estaba en su formación, la discusión de principios o criterios éticos, para regir la distribución de bienes en ese sector.

En el sistema sanitario costarricense el sector de profesionales formados en la concepción del modelo curativo-restaurativo de la salud ha visto fortalecida su posición por la vigencia de la lógica del mercado. Este sector, de forma consciente o inconsciente, ha ido persuadiendo a la población para que comparta esa concepción y, en consecuencia, modifique y aumente sus demandas de bienes sanitarios más coherentes con los objetivos económicos de grupos de interés que con las necesidades reales de las personas o las características epidemiológicas nacionales. De esta manera, tales demandas no surgen de las convicciones morales de la ciudadanía, sino de la manipulación que ejercen sobre ella dichos grupos, a quienes no les convienen pacientes autónomos, comprometidos con los principios éticos de la solidaridad del modelo de salud colectiva. 


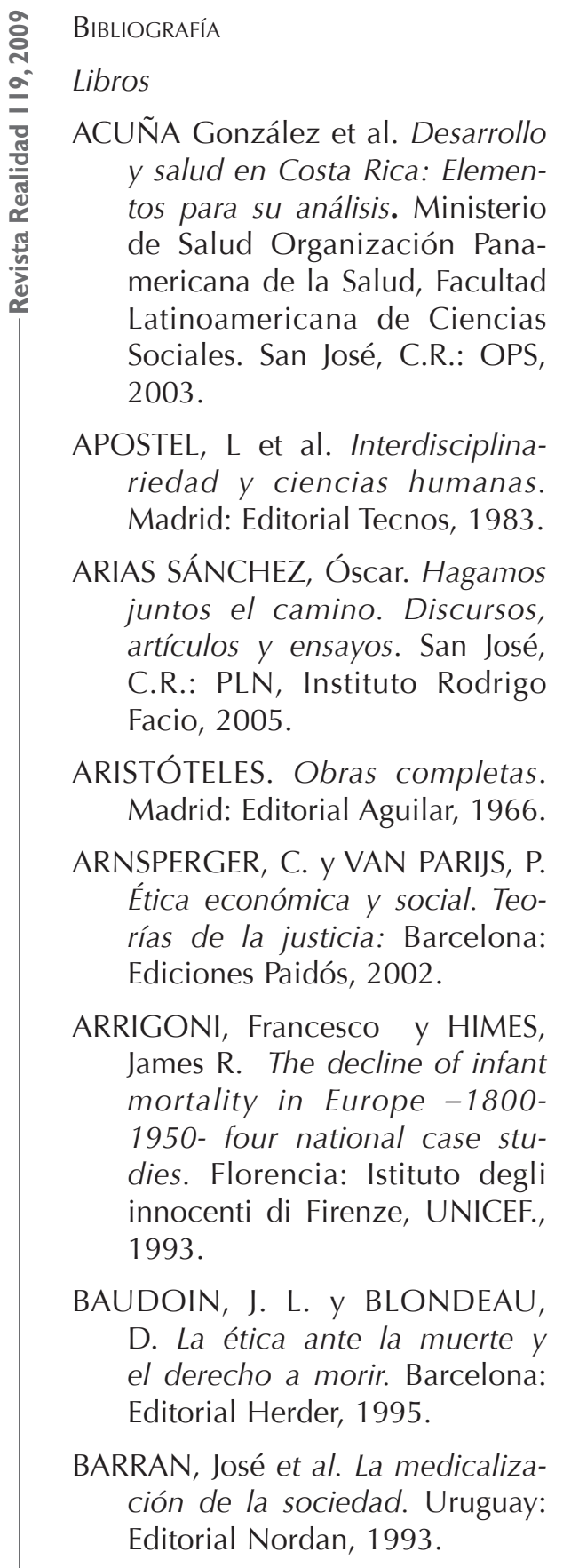

BARRY, Brian. Teorías de la justicia. Barcelona: Editorial Gedisa, 1989

BEAUCHAMP, T. y WALTERS, L. Contemporary issues in Bioethics. California: Wads pub., 1994.

BEAUCHAMP, TOm y CHILDRESS, James. Principios de ética biomédica. Barcelona: Editorial Masson, 1998

BENAVIDEZ GOMEZ, L. Introducción a la economía política. Madrid: Ediciones Pirámide, 1987.

BERLINGUER, Giovanni.: A doença. Sao Paulo: Ed. Hucitec, 1988. . Etica della salud. Milano: Il Saggiatore, 1997.

BERLINGER, G. e GARRAFA, V. La merce finale. Saggio sulla compraventa di parti del corpo umano. Milán: Baldini e Castoldi, 1996.

BERLINGUER, Gioanni. Medicina e politica. Bari: De Donato, 1973.

BERLINGUER, Giovanni y VOLNEI GARRAFA. La merce finale. Milano: Baldini i Gastoldi, 1996.

BETTETINI, Maria. Breve historia de la mentira. De Ulises a Pinocho. Madrid: Ediciones Cátedra, 2002.

BLANCO SEGURA, Ricardo. 1884. El estado, la iglesia y las reformas liberales. San José, Costa Rica: Editorial de Costa Rica, 1984. 
BLUM, Henrik. Planning for Health: Development and Application of Social Change Theory. New York: Human Sciences Press, 1974.

BOBBIO, Marco. Leggenda e realtà del colestoro. Le labile certezze della medicina. Turín: Bollati Boringuieri, 1993.

BOBBIO, Norberto. Liberalismo y democracia. México: Fondo de Cultura económica, 1989.

BOLADERAS, Margarita. Bioética. Madrid: Editorial Síntesis, 1998.

BORSELLINO, Patrizia. Bioetica tra autonomia e diritto. Milán: Editore Zadig, 1999.

BORTMAN, Marcelo. Indicadores de salud ¿Mejoró la equidad? Costa Rica 1980-2000. San José, C.R.: Ministerio Salud. Organización Panamericana de la Salud. Oficina Regional de la OMS, 2002.

BOURDIEU, Pierre. Cuestiones de sociología. Madrid: Ediciones Istmo, 2000.

BRENES ROSALES, R. Introducción a los derechos humanos. San José, Costa Rica: EUNED, 1992.

BRODY, Baruch. Life and Death Decisión Making. N. Y. : Oxford University Press, 1998.

CALLAHAN, Daniel et al. Los fines de la medicina. Barcelona: Edita Fundació Víctor Grífols i Lucas, 2004.

CALLAHAN, Daniel. What kind of life. Nueva York.: Simon and Schuster, 1990.
CAMPS, Victoria. Una vida de calidad. Barcelona: Editorial Crítica, 2001

CALSAMIGLIA, Albert. Cuestiones de lealtad. Barcelona: Ediciones Paidós, 2000.

CHADWICK, Ruth. Ethics, Reproduction and Genetic Control. Great Britain: Routledge, 1994.

CHARLESWORTH, Max. La bioética en una sociedad liberal. Gran Bretaña: Cambridge University Press, 1996.

COMANDUCCI, P. Contrattualismo, utilitarismo, garanzie. Turín: Giappichelli, 1984.

CARRANZA MAXERA, M. et al. Sólo Dios sabe por qué hace las cosas. Mortalidad materna en Costa Rica. San José, C.R.: EUNED, 2002

CASTORIADIS, Cornelius. La institución imaginaria de la sociedad. Barcelona: Tusquets, 1983. et al. La insignificancia y la imaginación. Diálogos. Madrid: Editorial Trotta, 2002.

COCKERCHAM, William. La SOciología de la medicina. Madrid: Editorial Pearson Educación, 2002

CONNIF, Richard. Historia natural de los ricos. Madrid: Taurus, 2003.

CONILL SANCHO, Jesús. Horizontes de economía ética. Madrid. Editorial Tecnos, 2004.

CORTINA, Adela. Hasta un pueblo de demonios. Ética pública y sociedad. Madrid: Taurus, 1998. 
COZZI, Donatella, NIGRIS, DanieIle. Gesti di cura. Turín: Editori: Coop. Colibrí, 1996.

CRUZ, Yalena de la. Los forjadores de la seguridad social en Costa Rica. San José. C.R. : EDNASSCCSS, 1995.

CHARLESWORTH, M. J. Bioethics in a Liberal Society. Cambridge University Press, 1993.

GINER, Salvador. Historia del pensamiento social. Barcelona: Editorial: Ariel, 1975.

DANIELS, N, KENNEDY, B. y KAWACHI, E. Is Inequality Bad for our Health? Joshua Cohen y Rogers (Eds.), Boston: 2000.

DEGOS, Laurent. Los transplantes de órganos. Madrid: Editorial Debate, 1994.

DESCARTES, René. Discurso del método. Meditaciones metafísicas. Madrid: Espasa-Calpe, 1970

DIETERLEN, Paulette. Ensayos sobre justicia. México: Distribuciones Fontamara, 1996.

ELIAS, Norbert. El proceso de la civilización. Investigaciones sociogenéticas y psicogenéticas. México: Fondo de cultura económica, 1989.

GINER, Salvador. Historia del pensamiento social. Barcelona: Editorial: Ariel, 1975.

ELSTER, John. Juicios salomónicos: Las limitaciones de la racionalidad como principio de decisión. Barcelona: Editorial Gedisa, 1999. ética de las decisiones médicas. Barcelona: Editorial Gedisa, 2000.

ENGELS, Federico. Escritos de juventud. México: Fondo de cultura económica, 1981.

ENGELHARDT, H. T. Los fundamentos de bioética. Barcelona: Ediciones Paidós, 1995.

ENRÍQUEZ, E. "El trabajo de la muerte de las instituciones", en: Käes, René, La institución y las instituciones. Buenos Aires: Paidós, 1990

ESTÉVEZ V., Agustín. Bioética. De la cuestión nominal a la caracterización de su concepto. Bahía Blanca, Argentina:Editorial de la Universidad Nacional del Sur, 2002.

FARRELL, M. D. Métodos de la ética. Buenos Aires: AbeledoPerrot, 1994.

FERNÁNDEZ BUEZO, Francisco. Ética y filosofía política. BarceIona: Edicions Bellaterra, 2000.

FLECK, Ludwick, La génesis y el desarrollo de un hecho científico. Madrid: Alianza Editorial, 1986.

FONTANA, Joseph. La historia de los hombres: el siglo XX. Barcelona: Editorial Crítica, 2002.

FOUCAULT, Michel. El nacimiento de la clínica. Una arqueología de la mirada médica. México: Editorial Siglo XXI, 1987.

La vida de los hombres infames. Argentina: Editorial Altamira, 1996. 
La política de salud en el siglo XVIII. Madrid: Editorial La Piqueta, 1991

FRAGA, Gabino. Derecho administrativo. México: Editorial Porrúa, 1969.

GALBRAITH, John Kenneth. Historia de la economía. Barcelona: Editorial Ariel, 1993

GARGARELLA, Roberto. Las teorías de la justicia después de Rawls. Barcelona: Ediciones Paidós, 1999

GRACIA, Diego. Fundamentos de Bioética. Madrid: Eudema, 1986.

GRACIA, Diego. Procedimientos de decisión en ética clínica. Madrid. Eudema, 1991.

GONZÁLEZ GUTIÉRREZ, Luisa. Escritos. Heredia, C.R.: EUNA, 2006

HANCOCK, Graham. Lords of poverty. The power, prestige and corruption of the international aid business. Nueva York: The Atlantic Monty Press, 1989

HARE, R. M. Ordenando la ética. Una clasificación de las teorías. Barcelona: Editorial Ariel, 1999.

HAYECK, Friedrich. Law, Legislation and Liberty. Chicago: University of Chicago Press, 1976.

HERRERA, María (compiladora) Jürgen Habermas: moralidad, ética y política. Propuestas y críticas. México: Alianza Editorial, 1993.

HERRERA, Reinaldo y LÓPEZ, Grettel (editores). Evolución demográfica de Costa Rica y su impacto en los sistemas de salud y pensiones. San José, C.R.: Academia de Centroamérica, 2004.

HERTZ, Noreena. El poder en la sombra. Las grandes corporaciones y la usurpación de la democracia. Buenos Aires: Editorial Planeta, 2002, p. 236

HOOFT, Pedro F. Bioética y Derechos Humanos. Temas y casos. Buenos Aires: Ediciones Desalma, 2004

HONGIU KOH, H. y SLYE, R (compiladores). Democracia deliberativa y derechos humanos. Barcelona: Editorial Gedisa, 2004.

HUERTAS, Rafael. Neoliberalismo y políticas de salud. España: Editorial: El Viejo Topo, 1998.

JARAMILLO ANTILLÓN, Juan. Historia y evolución del Seguro Social de Costa Rica: su primer hospital Dr. Rafael Ángel Calderón Guardia. San José, C.R.: EDNASS-CCSS, 2004

JONAS, Hans. Das Prinzip Verantwortung. Francfort: Insel, 1979. . Técnica, medicina y ética. Barcelona: Editorial Paidós, 1997.

JONSEN, A. TOULMIN, S. The abuse of Casuistry. A History of Moral Reasoning. Berkeley: University of California Press, 1988.

KANT, Immanuel. Fundamentación de la metafísica de las costum- 
bres. Madrid: Espasa Calpe, 1999.

La paz perpetua. Madrid: Espasa Calpe, 1999.

KUHSE, H. and SINGER, P. Bioetics. An Anthology. Massachusetts: Blackwell Publishers, 2001.

LALONDE, Michel. A new perspective on the health of Canadians. Canadá, Ottawa: Department of National Health and Welfare. 1974

LAPORTE, Joseph. Principios básicos de investigación clínica. Madrid, Ergon, 1993.

Los medicamentos. La eficacia comporta un riesgo. Barcelona: Editorial La Gaya Ciencia, 1978

LASKI, H. J. El liberalismo europeo. México: Fondo de Cultura Económica, 1984.

LAURELL, A. La reforma contra la salud y la seguridad social. México, Ediciones Era, 1997.

LECALDANO, Eugenio. Bioética. Le scelte morali. Roma: Editori Laterza e Figli, 1999.

LOLAS, Fernando. Bioética. El diálogo moral en las ciencias de la vida. Chile: Editorial Universitaria, 1998.

LÓPEZ, María Elena et al. Costa Rica, las políticas de salud en el umbral de la reforma. San José, C.R.: UNICEF, 1997.
LÓPEZ DE LA VIEJA, M.T. Principios morales y casos prácticos. Madrid: Editorial Tecnos, 2000.

LÓPEZ, G. y ORTÚN, V. EConomía y salud. Fundamentos y políticas. Madrid: Ediciones Encuentro, 1998.

LOURAU, René. El análisis institucional. Argentina: Amorrortu editores, 1991.

MC KEOWN, Thomas. El papel de la medicina. ¿Sueño, espejismo o némesis? México: Siglo XXI, 1982.

MACKIE, J. L. Ética. Barcelona: Editorial Gedisa, 2000.

MACKLIN, Ruth. Dilemas. Argentina: Editorial Atlántida, 1992

MAFFETONE, S. e VECA, S. L' idea di giustizia da Platone a Rawls. Roma: Laterza e Figli, 1997.

MAINETTI, José. Compendio bioético. Argentina, La Plata: Editorial Quirón, 2000. . Ética médica. Argentina. La Plata: Quirón, 1989.

Agenda Bioética. Knock o la medicalización de la vida. La Plata: Editorial Quirón, 2005.

MALAVASSI AGUILAR, A. P. Entre la marginalidad social y los orígenes de la salud pública: leprosos, curanderos y facultativos en el Valle Central de Costa Rica. San José, Costa Rica: Editorial de la Universidad de Costa Rica, 2003. 
MARLASCA, Antonio. Introducción a la bioética. Heredia, C.R.: Facultad de Filosofía y Letras, Universidad Nacional, 2001.

Introducción a la ética. San José, Costa Rica: Editorial EUNED, 1997.

MARTíN, Mateo. Bioética y derecho. Barcelona: Ariel, 1987.

MARTÍNEZ FRANZONI, J. Ver para creer: la información pública ciudadana en América Central. Un estudio de la sociedad civil. San José, C.R.: Fundación Acceso, 2003.

y MESA LAGO,

C. Las reformas inconclusas: pensiones y salud en Costa Rica. San José, Costa Rica: Edición Fundación Friedrich Ebert, 2003.

MILL, John Stuart. El utilitarismo. Madrid: Alianza Editorial, 2005.

MIRANDA, Guido. La Seguridad Social y el Desarrollo en Costa Rica. San José, C.R.: EDNASS/ CCSS, 1994.

MIRANDA, Guido et al. La construcción de la Seguridad Social. Antecedentes de la enseñanza y práctica de la medicina. San José, C.R. EUNED, 2004

MYLES, John F. Old age in the Welfare State. Boston: Little, Brown. 1984.

MOLINA, Iván y PALMER, Steven. El paso del cometa. San José, C.R. Editorial EUNED, 2005.
MORGAN, Lynn. Participación Comunitaria en salud: la política de atención primaria en Costa Rica. San José: C.R. EDNASSSCCSS, 1997.

MORIN, Edgar. Introducción al pensamiento complejo. Barcelona: Editorial Gedisa, 2005.

MOYA, Ligia. Introducción a la estadística de la salud. San José: Editorial de la Universidad de Costa Rica, 2002.

NINO, Carlos. Ética y derechos humanos. Un ensayo de fundamentación. Barcelona: Ariel, 1987.

NOZICK, Robert. Anarquía, Estado y utopía. México: Fondo de cultura económica, 1988.

OFFE, Clauss. Contradicciones en el Estado del bienestar. Madrid: Alianza Editorial, 1990.

ORTIZ GUIER, Juan Guillermo. Epopeya ramonense: parte de la odisea de San Ramón en el siglo XX. San José: Editorial Mirambell, 2001.

PALMER, Steven. From Popular Medicine to Medical Populism. Doctors, Healers, and Public Power, 1800-1940. United States: Duke Univesity Press, 2003.

PARSONS, Talcott. The Social System. New York: Free Press, 1951.

PASSERIN d'ENTREVES, Maurizio. Modernity, Justice and Community. Milán, Franco Angeli, 1990. 
PETRAS, James. Imperio vs. resistencia. La Habana: Casa Editora Abril, 2004.

PICADO, Gustavo et al. Gasto y financiamiento de la salud en Costa Rica: situación actual, tendencias y retos. San José, C.R.: Organización Panamericana de la Salud, Ministerio de Salud, Caja Costarricense del Seguro Social, 2003.

PLATZ, Mark. Dilemas éticos. México: Fondo de Cultura Económica, 1997.

PONTARA, Giuliano. Filosofía práctica. Milán: Il saggiatore, 1987.

PORTER, Roy. Breve historia de la medicina. De la antigüedad hasta nuestros días. Madrid: Taurus, 2002.

PORTILLO, José et al. La medicalización de la sociedad. Montevideo, Uruguay: Editorial NordanComunidad, 1993.

RAMÍREZ AMADOR, E. Hablemos de gerencia: un enfoque futurista. San José, Costa Rica: Editorial Alma Mater, 1994.

RAWLS, John. Sobre las libertades. Barcelona: Ediciones Paidós, 1990

Teoría de la justicia. España: Fondo de cultura económica, 2002.

RAZETO, Luis. Economía popular de solidaridad y mercado democrático. Santiago, Chile, 1988.
RENOUWIN, Pierre. Historia de la relaciones internacionales siglos XIX y XX. Madrid: Akal, 1982.

RICKEN, Friedo. Ética general. Barcelona: Editorial Herder, 1987.

RODRÍGUEZ ECHEVERRÍA, Miguel Ángel. Al progreso por la libertad. San José: Editorial Libro Libre, 1988.

ROJAS Margarita (compiladora). Luisa González Gutiérrez. Escritos. Heredia, C.R.: EUNA, 2006.

ROSALES POSAS, Ramón. Formulación y evaluación de proyectos. Instituto Centroamericano de Administración Pública. San José- Costa Rica, 2000.

ROSENBERG, Mark. Las luchas por la seguridad social en Costa Rica. San José: Editorial Costa Rica, 1983

ROVIRA MAS, Jorge. Estado y política en Costa Rica: 1948-1970. San José: Editorial de la Universidad de Costa Rica, 2000

RUIZ CALDERÓN, J .M. Nuevas cuestiones de bioética. Pamplona: Eunsa, 2002.

SCANNONE, J. C. Ética y economía. Buenos Aires: Editorial Bonum, 1998.

SCHWARTZ, Barry. Por qué más es menos. La tiranía de la abundancia. Madrid: Taurus, 2004.

SWANITS, Dietrich. La cultura. Todo lo que hay que saber. Madrid: Editorial Taurus, 2002. 
SAN MARTIN, Hernán. La crisis mundial de la salud. ¿Salud para nadie en el año 2000? Madrid: Editorial Ciencia, 1985.

SEN, Amartya. Bienestar, justicia y mercado. Ediciones Paidós, 1990

----- . El nivel de vida. Madrid: Editorial Complutense, 1998

- - - - Nuevo examen de desigualdad. Madrid: Alianza Editorial, 1999.

- - - - - Sobre ética y economía. Madrid: Alianza Editorial, 1999.

SENENT de FRUTOS, J. A. Ellacuría y los Derechos Humanos. Bilbao: Editorial Desclée de Brouwer, 1998.

SILVEIRA da, Pablo. John Rawls y la justicia distributiva. Madrid: Campo de ideas, 2003.

SILVERMAN, Milton y LEE, Philip. Píldoras, ganancias y política. México: Editorial Siglo XXI, 1983.

SINGER, Peter. A Companion to Ethics. Cambridge, Basil Blackwell, 1991

- - - - Ética práctica. Barcelona: Editorial Ariel, 1984.

- - - - Una vida ética. Madrid: Taurus, 2002.

SMITH, ADAM. La riqueza de las naciones. México. Fondo de Cultura Económica, 1994.
- - - - - Teoría de los sentimientos morales. México: Fondo de Cultura Económica, 1983.

SMITH, Trevor. Ethics in Medical Research. Cambridge University Press, 1999.

SOLÍS, Manuel y ESQUIVEL, Francisco. Las perspectivas del reformismo en Costa Rica. San José: Coedición: DEI-EDUCA, 1980.

SONTAG, Susan. La enfermedad y sus metáforas. El sida y sus metáforas. Madrid: Taurus, 1996

STIGLITZ, Joseph. El malestar en la globalización. Buenos Aires: Taurus, 2002

. La economía del sector público. Barcelona. Editorial: Antoni Bosch, 2000.

. Los felices noventa. La semilla de la destrucción. Madrid: Taurus, 2003 Macroeconomía. Barcelona: Editorial Ariel, 1998.

STONE, Samuel. La dinastía de los conquistadores. San José: EDUCA, 1975.

- El legado de los conquistadores. Costa Rica: EUNED, 1998

TERRIS, Milton. La revolución epidemiológica y la medicina social. Madrid: Siglo Veintiuno Editores, 1987.

THOMPSON, Mel. Ethics. Londres: Hooder and Stoughton, 2000 
TSCHUDIN, Verena et al. Ethics. Aspects of Nursing Care. Londres Scutari Press, 1993.

TOURAINE, Alain et al. El misterio argentino. Buenos Aires: Editorial El Ateneo, 2003.

TUGENDHAT, Ernest. Problemas de la ética. Barcelona: Editorial Crítica, 1988.

VALLS, Ramón. Ética para la bioética, y a ratos para la política. Barcelona, Editorial Gedisa, 2003.

VALVERDE CASTRO, C y SÁENZ B., B. La reforma del Sistema Nacional de Salud: estrategias, avances y perspectivas. San José, Costa Rica: Ministerio de Planificación Nacional y Política Económica, 1998.

VIAFORA, Corrado. Fondamenti di Bioetica. Milán: Casa Editrice Ambrosiana, 1989.

VIRCHOW, Rudolf. Cellular Pathology. Nueva York, 1971.

WATARU, Ohashi. Manual de diagnosis oriental. Barcelona: Editorial Urano, 1995.

WATSON, Richard. Descartes. El filósofo de la luz. Barcelona: Editorial Bergara, 2003

WEBER, Max. El político y el científico. La política como vocación. Madrid: Alianza Editorial, 2004.

WONNACOTT, P. y WONNACOTT, R. Economía. Madrid: Mc Graw Hill/ Interamericana de España, 1987.
WRONG, Dennis H. La población. Buenos Aires: Editorial Paidós, 1968,

Artículos de revistas

ABRAMOVITZ, Mimi.The privatization of the Welfare State. En Rev. Social Work, jul-aug:, 1986, pp. 257-264.

AGICH G. y BEGLEY C. 1985. Some problems with pro-competition reforms. En Rev. Social Science and Medicine, 1985, 21(6):623630.

ARDOINO, Jacques. L'aproche multiréférentielle (pluriele) des situacions éducatives et formatives. En: Revue Pratiques de formation, Analyse. No 25-26, Universidad de París VIII, París, 1993, p.15

BAILEY, Robert. Uses and Misuses of privatization. En Rev. Prospects for privatization, Hanke, Steve (Ed.) New York, The Academy of Political Science, 1987 pp. 138-152.

BRICEÑO, Rodrigo. Análisis CostoBeneficio del Proceso de Reforma en Salud. En: Sanigest Internacional, junio, 2003, p.1

BUCK, Carol. Después de Lalonde: Hacia la generación de salud. En: Canadian Journal of Public Health 76. Suplemento 1, mayo/junio de 1985, p.13

CALLAHAN, Daniel, Bioethics as a Discipline. En: Hasting Center Report, 1, 1973, pp.66-73. 
CAJA COSTARRICENSE DEL SEGURO SOCIAL. El compromiso de gestión: teoría y evidencia. En: Gestión. Revista de Ciencias Administrativas y Financieras de la Seguridad Social. Volumen 5, número extraordinario, 1997.

CONILL, Jesús. Justicia Sanitaria y economía ética. En: Bioética. Número Especial. Fascículo No 5, vol. IV, 2004, p.6.

DÉSAULTELS, Jacques y LAROCHELLE, Marie Larochelle. Educación científica: el regreso del ciudadano y de la ciudadana. En: Enseñanza de las ciencias, 200321 (1), p.3-20.

DIEZ ROUX, Ana. On Genes, Individuals, Society, and Epidemiology. Am J Epidemiology, 1998, 148: 1028 .

DURAN, Fabio y QUESADA, Rodolfo. En: Gestión. Vol.5, Primer Semestre, 1997, p.11.

FERNÁNDEZ DÍAZ, J.M. Gaceta Sanitaria. 1 oct., 2001, vol.15, No 05, pp.453-460.

GARNIER RÍMOLO, Leonardo. EI seguro de salud en Costa Rica: la encrucijada de un modelo exitoso. En Gaceta médica de Costa Rica, Suplemento No 2, 2006, p.49

GARRY, Ann. Medicine and medicalization: A response to Purdy. En Bioethics, vol. 15 no 3, 2001, pp.262-269.

GUERRA ROMERO, L. La medicina basada en la evidencia: intento de acercar la ciencia a la práctica médica, En Medicina clínica (Barc); 1996.

GOODMAN, Kenneth W. Philosophy as news: Bioethics, journalism and public policy. En Journal of Medicine and Philosophy, 1999, 24: pp.181-200.

HOMEDES, Núria. Privatización de los servicios de salud: las experiencias de Chile y Costa Rica. En Gaceta Sanitaria. vol.16 no.1 Barcelona Feb. 2002, p.1-15

HOMEDES, Núria y UGALDE, Antonio. Why neoliberal health reforms have failed in Latin American. Health Policy, 7 (2005), pp. 83-96.

JIMÉNEZ NAVARRETE, M. Fco et al. Las organizaciones de la salud, la reforma del sector y la nueva gerencia: una revisión. En Gestión: vol.5 no 1, Primer semestre, 1997, p.29.

LOLAS STEPKE, Fernando. EI rol testimonial del médico. Una reflexión bioética crítica. En: Folia Humanística. jul/ago. Tomo XXIX, n. 321, 1991, p. 313

MARLASCA, Antonio. Del trabajo como castigo al trabajo como derecho. En: Revista Medicina Legal de Costa Rica. San José, C.R., vol.22, No2, setiembre, 2005.

MARTÍNEZ FRANZONI, Juliana. Poder y alternativas: la disponibilidad de agendas internacio- 
nales en las reformas de la salud en Costa Rica, 1988-1998, en: Anuario Centroamericano de Estudios Sociales, vol. 25 (1), p.2.

PUIG, J., PINTO-PRADES J.L. Y ORTÚN-RUBIO, V. El análisis coste-beneficio en sanidad. Departamento de economía y empresa. Centro de investigación economía y salud. Universidad Pompeu Fabre. Barcelona, en Atención Primaria 2001; vol 27, Num.6, 15 de abril 2001, pp. 421-427.

PURDY, Laura. Medicalization, medical necessity, and feminist medicine, en Bioethics, vol. 15 no 3, 2001, pp.

SALAS, Alvaro. Una conquista invaluable. En: Gestión. Vol.5 Número Extraordinario, 1997, p.21.

SEN, Amartya. Markets and Freedoms: Achievements and Limitations of the Market Mecanism in Promoting Individual Freedoms. En: Oxford Economic Papers 45, 1993.

VILLALBÍ, Joan R. et al. El proyecto internacional de ciudades limpias. En Rev.: Anthropos. Sociedad Urbana y salud. No118119, marzo-abril, 1991.

VIRCHOW, Rudolf. Collect Essays. En: Public Health and epidemiology. Editado y prologado por L.J. Rather, 1985.
ARTÍCULOS DE PERIÓDICOS

ARCE MONTIEL, María de los Ángeles. Primeras respuestas a una imagen olvidada. La Nación. Campo Pagado.Costa Rica, domingo 26 de junio del 2005, p.11A (Sección: El país).

ÁVALOS, Ángela. CCSS podría recortar servicios. La Nación. Costa Rica, miércoles 19 de enero del 2005, (Sección: El país).

ÁVALOS, Ángela. 112.000 enfermos en listas de espera para cirugía o examen. La Nación. Costa Rica, lunes 20 de marzo del 2006, 5A. (Sección: El país).

ÁVALOS, Ángela. 4000 toneladas de bienes sin uso en bodegas de CCSS. La Nación. Costa Rica, sábado 7 de mayo del 2005, 4A, (Sección: El país)

ÁVALOS, Ángela. Mucha vida después de los ochenta años. La Nación. Costa Rica, domingo 22 de agosto del 2004, 4A (Sección: El país).

ÁVALOS, Ángela. Paciente murió tras esperar 3 años cirugía. La Nación. Costa Rica, miércoles 25 de mayo del 2005, página 12A (Sección: El país)

ÁVALOS, Ángela. País con histórica baja de la mortalidad infantil. La Nación. Costa Rica, jueves 7 de abril del 2005, p.16 A (Sección Salud y Familia) 
ÁVALOS, Ángela. Se debe extender el seguro de salud. La Nación. Costa Rica, lunes 10 de octubre del 2005, 8A (Sección: El país).

BERMÚDEZ, Manuel. La guerreras invisibles del 56. La Nación. Costa Rica, viernes 19 de mayo del 2006, p.2. (Áncora).

CANTERO, Marcela. Tres periodistas de "La Nación" ganan el premio Ortega y Gasset. La Nación. Costa Rica, sábado 23 de abril del 2005, p.14A. (Sección Artes y Letras).

CORVO, Vittorio, PETRELLA Ricardo y MORIN, Edgar. El foro de intelectuales arranca con duras críticas al liberalismo. El país. España, jueves 27 de enero, 2000, p.39. (Sección: La cultura).

GARTEN, Jeffrey. ¿Deberíamos preocuparnos? En: Newsweek, 17 de octubre de 2005, p.33.

JARA, Eladio. La Nación. Costa Rica, lunes 8 de mayo del 2006, p.15. (Sección: Opinión).

OVIEDO, Esteban y HERNÁNDEZ, Carlos. Migración nicaragüense deja de crecer. La Nación. Costa Rica, domingo 4 de junio del 2006, p.4A (Sección, El país)

ROSERO BIXBY, Luis. Pastos COmunales, los "montados" y la CCSS. La Nación. Costa Rica, domingo 31 de julio del 2005, p.37 A (Opinión)

SOLANO MADRIGAL, Ricardo. Justa Sindical. La Nación. Costa
Rica, miércoles 17 de enero de 2001.

UNDERHILL, William. El plomero polaco. En: Newsweek. En español. No 1042, 11 de oct., 2005.

La Tribuna. Costa Rica, 19 de mayo de 1940.

Documentos, memorias, boletines

ANDREAZZI, María. Procesos de privatización en el sector salud. Caso Brasil. Informe de consultoría preparado para el Programa de Desarrollo de Políticas de Salud de la Organización Panamericana de la Salud, Washington, D.C., 1991.

BANCO Mundial (BM). El financiamiento de los servicios de salud en los países

en desarrollo. Una agenda para la reforma. Boletín de la Oficina Sanitaria

Panamericana.1987, 103(6):695709.

BANCO Mundial (BM). Costa Rica: Identifiying the social needs of the poor: An update. Washington. Central America Department, Latin American and Caribbean Region Report, No 15449-CR.

CAJA Costarricense del Seguro Social (CCSS). Agenda estratégica de la Caja Costarricense del Seguro Social 2004-2006. CCSS. Presidencia Ejecutiva, octubre, 2004. 
CAJA Costarricense del Seguro Social (CCSS). Código de ética del servidor de la Caja Costarricense del Seguro Social. CCSS. Programa institucional de rescate y formación de valores. Aprobado por Junta Directiva, en sesión número 7308 , artículo $15^{\circ}$ de fecha 25 de febrero de 1999.

CAJA Costarricense del Seguro Social (CCSS). Hacia un nuevo modelo de atención integral en salud. Gerencia modernización. San José, Costa Rica: CCSS, 1998.

CAJA Costarricense del Seguro Social (CCSS). Hacia un nuevo sistema de asignación de recursos. Proyecto de modernización. San José, Costa Rica: CCSS, 1997.

CAJA Costarricense del Seguro Social (CCSS). Ley No 7852. Desconcentración de los hospitales y clínicas de la CCSS. Reglamentos de las juntas de salud. Reglamento a la ley 7852. San José, Costa Rica: CCSS, 2000.

CAJA Costarricense del Seguro Social (CCSS). Resumen plan institucional de promoción de la salud. Gerencia de modernización y desarrollo. Área de promoción de la salud. Región Brunca. San José, Costa Rica: CCSS, 1999.

CLARK, Mary A. Health Sector Reform in Costa Rica: Reinforcing a Public System. Prepared for the Woodrow Wilson Center
Wokshops on the Politics of Education and Health Reforms. Washington, D.C. Tulane University. April 18-19, 2002.

COSTA RICA. Ley No 7852. Desconcentración de los hospitales y clínicas de la Caja Costarricense del Seguro Social. En la Gaceta No 250 del 24 de diciembre de 1998.

COSTA RICA. Ley Constitutiva de la Caja Costarricense de Seguro Social. Reglamento Invalidez, Vejez y Muerte. San José, C.R.: EDITEC EDITORES, 2004.

COSTA RICA. (Ley general de salud) Ley general de salud. San José: Costa Rica: IJSA, enero del 2002.

COSTA RICA. Proyecto de Reforma del Sector Salud. Componente de readecuación del modelo de atención. San José, C.R.: Unidad Preparatoria de Proyectos 001, mayo de 1993.

CHACÓN, Dunia y FERNÁNDEZ, Álvaro. Comisión Investigadora de la Caja Costarricense del Seguro Social. Informe de mayoría. Rendido al señor Presidente de la República, Dr. Abel Pacheco de la Espriella, septiembre de 2004.

El estado del mundo. Anuario económico geopolítico mundial 2002. Madrid: Ediciones Akal, 2001.

GOODMAN, Kenneth W. Los medios de comunicación: éxitos, errores y deberes al informar 
sobre temas bioéticos, ponencia presentada en el Quinto Congreso de Bioética, América Latina y el Caribe. Panamá, del 9 al 13 de agosto, 2005.

MARTÍNEZ FRANZONI, Juliana. Régimen de bienestar y salud en Costa Rica: una década de reformas y mercantilización de servicios. Documento presentado en la conferencia Latin American perspective on public health. Universidad de Toronto, 5-7 de mayo del 2005, p.12.

GLOBAL Forum for Health Research .The 10/90 Report on Health Research 2000. Switzerland: Published by the Global Forum for Health Research, 2001.

GRACIA, Diego. Investigación con sujetos humanos: implicaciones lógicas, históricas y éticas. OPS/ OMS. Programa regional de bioética. Primera reunión del comité asesor internacional en bioética del 10 al 12 de mayo, 1999, Washington, D.C. EEUU.

LEÓN, M. y SÁNCHEZ, R. Determinación de la equidad, eficiencia, calidad y cobertura de los servicios de salud en el modelo tradicional de asignación de recursos financieros, comparado con un nuevo modelo, Costa Rica 1995-1997. (Informe Final). Costa Rica: Centro Interamericano de Estudios de Seguridad Social (CIESS), Department of International Development (DFID), University of York, 1998.
MINISTERIO de Salud (MS). Análisis sectorial de salud. Ministerio de Salud. San José, C.R.: El Ministerio, 2002.

MINISTERIO de Salud, CCSS, AyA, OPS. Indicadores de Salud Cantonales Costa Rica. Ministerio de Salud, Caja Costarricense del Seguro Social, Instituto Costarricense de Acueductos y Alcantarillados, Organización Panamericana de la Salud, Organización Mundial de la Salud. San José, C.R., 2002.

MINISTERIO de Salud (MS). Memoria Anual 1999. San José, C. R. Ministerio de Salud, 1999.

MINISTERIO de Sanidad y Consumo. Salud: la llave del desarrollo. Jornada de Cooperación Sanitaria. Madrid: Edición: Proyectos y Producciones Editoriales Cyan, 1998.

OFICINA Nacional del Censo. Estadística Vital (1906-1925). Publicación no 1: San José, C.R. Oficina Nacional del Censo, Imprenta Lehmann, 1927.

ORGANIZACIÓN Mundial de la Salud (OMS). Alma-Ata 1978: Atención primaria de la salud. Serie Salud para todos. No 1. Ginebra: OMS, 1978.

ORGANIZACIÓN Panamericana de la Salud (OPS). Representación en Costa Rica.100 años de salud -Costa Rica: Siglo XX. San José, C. R.: Organización Panamericana de la Salud, 2003. 
ORGANIZACIÓN Panamericana de la Salud (OPS). Salud, equidad y transformación productiva en América Latina y el Caribe. Versión preliminar del documento que se presentó en la XXIV Conferencia Sanitaria Panamericana. Washington, USA, septiembre, 1994, p.90

ORGANIZACIÓN Mundial de la Salud (OMS). Alma-Ata 1978: Atención primaria de la salud. Serie "Salud para todos", № 1. Ginebra: OMS, 1978.

ORGANIZACIÓN Panamericana de la Salud/Organización Mundial de la Salud. La Cooperación de la Organización Panamericana de la Salud ante los Procesos de Reforma del Sector Salud. Washington, D.C: OPS/OMS., 1997.

PROGRAMA de las Naciones Unidas para el Desarrollo (PNUD). Informe sobre Desarrollo Humano 2000. Madrid: Ediciones Mundi Prensa, 2000.

PROGRAMA de las Naciones Unidas para el Desarrollo (PNUD). Ética y Desarrollo Humano. Simposio Regional sobre Ética y Desarrollo sustentable. Foro de Ministros de Medio Ambiente de América Latina y el Caribe. Programa de Naciones Unidas para el Desarrollo. BogotáColombia, 2002.

PROYECTO Estado de la Nación. Estado de la Nación 1997. En Desarrollo Humano Sostenible. San José, C.R. 1997.

PROGRAMA Estado de la Nación. Décimo Informe: Estado de la Nación en Desarrollo Humano Sostenible. San José, Costa Rica: Proyecto Estado de la Nación, 2004.

$\mathrm{SOJO}$, Ana. Hacia unas nuevas reglas del juego: Los compromisos de gestión en salud de Costa Rica desde una perspectiva comparativa. Serie Políticas Sociales 27. Comisión económica para América Latina y el Caribe, Santiago de Chile, 1998.

UNICEF-Ministerio de Salud. Costa Rica, las políticas de salud en el umbral de la reforma. San José: C.R. UNICEF, 1997-.

UNIVERSIDAD NACIONAL- IDESPO. La población costarricense de la gran área metropolitana frente a su compromiso hacia la lectura. Pulso No 9, ago, pp.441, 2000.

UNIVERSIDAD NACIONAL- IDESPO. Percepciones de la ciudadanía sobre educación. Hábitos de lectura. Pulso. No 26, 2004. 

sobre la irrealidad de la competencia perfecta: "No hay una reestructuración de la configuración económica resultante que sitúe a un consumidor en una perspectiva mejor, sin perjudicar a otro (en vista de sus preferencias). No son posibles ulteriores intercambios mutuamente ventajosos. Tampoco hay otros procesos productivos factibles que produzcan más de ciertos codiciados artículos in requerir cortes en otros, ya que si esto no fuera así, la situación de algunos podria ser más ventajosa sin que bubiese pérdidas para nadie. La teoría del equilibrio general explica cómo, dadas las condiciones apropiadas, la información suministrada por los precios lleva a los agentes económicos a actuar por medios encaminados a conseguir este resultado. La competencia perfecta es un procedimiento perfecto respecto a su eficiencia. Desde luego, las condiciones requeridas son muy especiales y rara vez se dan en su totalidad en el mundo real." Cf.: Teoría de la justicia. Fondo de cultura económica, Madrid, 1995, pp.254-255.

6 Sobre el tema de economía solidaria, véase Razeto, Luis. Economía popular de solidaridad y mercado democrático. Santiago, Chile, 1988. tratara de una fábrica en el modelo tayloriano; en concordancia con esa práctica, los criterios que se siguen para evaluar la calidad de la atención es cuantitativa: una medición poco realista, aunada a las dificultades que genera una información imperfecta y costosa.

4 Véase, por ejemplo, Conill, Jesús. Horizontes de la economía. Madrid: Editorial Tecnós, 2004, pp.257-260.

7 Jaramillo Antillón, Juan. Historia y evolución del Seguro Social de Costa Rica: su primer hospital Dr. Rafael Ángel Calderón Guardia. San José, C.R.: EDNASS-CCSS, 2004, pp. 190,191.

8 Arias Valverde, Óscar. La prestación de servicios médicos de la CCSS a través de cooperativas. En: Revista Jurídica de Seguridad Social. San 


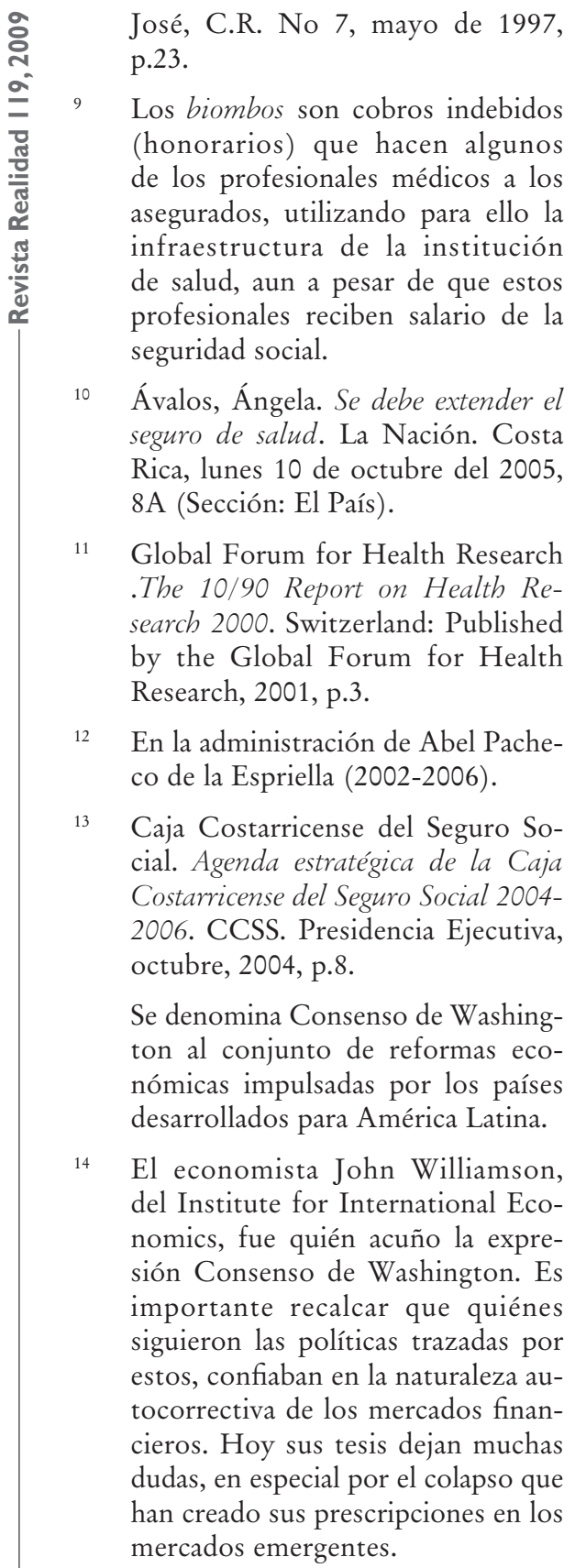

Rodrigo Gutiérrez: "Los médicos de los siglos XIX y XX, en Costa Rica, igual que lo fue en otras partes, les parecía aceptable y lógico que la bigiene y la salud pública estuvieran separadas de la práctica de la medicina clinica. Esa fue la visión liberal dominante de ese entonces que se proyectará, hasta nuestros días, en un importante sector de profesionales. La visión del médico era que la "higiene y la salud pública son responsabilidad del Gobierno y de la gente"; al Estado le correspondia legislar, vigilar, inspeccionar y castigar las infracciones $y$ a la gente el aseo de sus casas, de sus predios, alimentarse, educarse, cuidarse. Si se enfermaban, les correspondía buscar asistencia. (...) El médico atendia si le pagaban. Esa era su profesión. El médico asistía al hospital de caridad para atender a los pobres, algunas veces sin cobrar salario. En esa "práctica hospitalaria" adquiría experiencia y destrezas; atendía a "los pudientes" en su clínica privada. También era lícito que el médico recibiera honorarios por atender, en forma particular, a un paciente pobre internado en los hospitales de caridad. Para los pobres de las ciudades y comarcas cercanas, que podian trasladarse por su cuenta, estaba el hospital y las unidades sanitarias. Para los más solventes, la consulta privada de los médicos y los servicios de pensionado en clinicas y hospitales privados o estatales. Para los pobres que no podian trasladarse y para la población rural, los conocimientos populares (...) y la Mano de Dios. (...) La práctica liberal de la medicina se concebía como la de un abogado, un ingeniero o un farmacéutico, sólo que los médicos tenian grandes ingresos porque 
eran pocos y sus servicios eran caros y muy apreciados". Cf. Guido Miranda (Compilador). La construcción de la seguridad social. Antecedentes de la enseñanza y práctica de la medicina. San José, C.R.. EUNED,2004, pp.162,163.

Sobre esto Eladio Jara afirma: "Las instituciones autónomas funcionaban muy honestamente cuando el presidente de la República solo podía nombrar un miembro de cada directiva por año, pero eso era una calamidad, no se podía meter la mano en las instituciones porque entonces si eran autónomas, como lo ordena la Constitución...a alguien se le ocurrió poner directivas con cuatro miembros del Gobierno y tres de la oposición, pero eso nunca funcionó. En el gobierno que termina, las directivas han tenido los siete miembros del partido que ha gobernado y el gerente, que antes era un técnico experimentado que ejercía la misión ejecutiva en cada entidad, abora lo convirtieron en ayudante del presidente ejecutivo, que es nombrado por el gobernante, no por sus méritos académicos, sino por politica." La Nación. Lunes 8 de mayo del 2006, p.15. (Opinión).

17 Cf. Guido Miranda .La construcción de la seguridad social. Antecedentes de la enseñanza y práctica de la medicina. San José, C.R.. EUNED,2004,p. 147.

18 Callahan, Daniel et al. Los fines de la medicina. El establecimiento de prioridades nuevas. Introducción Victoria Camps, Fundatió Víctor Grífols i Lucas, Barcelona, 1999, p. 5. 